\title{
True Prevalence of Resistant Hypertension
}

\author{
Andréa Rodrigues Sabbatini ; Vanessa Fontana ${ }^{1}$ e Heitor Moreno Jr². \\ Cardiovascular Pharmacology Laboratory, Departmentof Pharmacology, Faculty of Medical Sciences, State University of Campinas ${ }^{1}$; Resistant \\ Hypertension Unit, Department of Internal Medicine, Faculty of Medical Sciences, State University of Campinas², SP - Brazil
}

\section{Dear Editor,}

The true prevalence of resistant hypertension (RHT) is unknown, at least in part because its definition is not consistent worldwide. We have read with great interest the article by Massierer et al. (1) showing that the frequency of patients with true RHT is lower (3.0-4.5\% of the general hypertensive population) in clinical settings when compared to $14.5 \%$ estimated in the Spanish ABPM Registry ${ }^{(2)}$. In our opinion, the latter estimates do not completely account for uncontrolled hypertension secondary to undertreatment and poor adherence, for example. Thus, the present findings are probably much closer to the real prevalence of RHT considering that errors due to inconsistencies in defining RHT, lack of strict criteria for inclusion of patients and absence of quality control of the data were correctly taken into account.

\section{Keywords}

Hypertension; Prevalence; Medication Adherence.

Mailing Address: Heitor Moreno-Júnior •

Rua Jasmin, 850, Apto. 33, Primavera. Postal Code 13087-460, Campinas, $\mathrm{SP}-$ Brazil

E-mail: hmoreno@cardiol.br, hmoreno@uol.com.br

Artigo recebido em 24/07/12; revisado em 24/07/12; aceito em 23/0812.

\section{References}

1. Massierer D, Oliveira AC, Steinhorst AM, Gus M, Ascoli AM, Goncalves SC, et al. Prevalence of resistant hypertension in non-elderly adults: prospective study in a clinical setting. Arq Bras Cardiol. 2012;99(1):630-5.

\section{Reply}

We appreciate your interest in our work ${ }^{1}$. To establish the real frequency of diseases is essential for the planning of care and resource allocation. Sometimes the estimates are artificially increased due to selection biases. This appears to be the present issue on the prevalence of resistant hypertension. I agree with the colleagues regarding the understanding that this prevalence is overestimated. Variable definitions and case selection in unrepresentative samples contribute to that, but it is worth noting that many patients have this condition because of insufficient treatment adherence. In pragmatic terms, patients with high blood pressure because they are not using blood pressure drugs are at similar risk to those who use the medication and
2. de la Sierra A, Banegas JR, Oliveras A, Gorostidi M, Segura J, de la Cruz JJ, et al. Clinical differences between resistant hypertensives and patients treated and controlled with three or less drugs. J Hypertens. 2012;30(6):1211-6.

show inadequate response. Regarding the former, we should employ all the techniques and efforts to convince them to take the medication; as for the latter, which have a less frequently observed condition, advanced diagnostic and therapeutic methods should be used to treat them.

\section{Sincerely,}

Flávio Danni Fuchs, Daniela Massierer, Ana Claudia Tonelli de Oliveira, Ana Maria Steinhorst, Miguel Gus, Aline Maria Ascoli, Sandro Cadaval Gonçalves, Leila Beltrami Moreira, Vicente Correia Jr, Gerson Nunes, Sandra Costa Fuchs

\section{Reference}

1. Massierer D, Oliveira AC, Steinhorst AM, Gus M, Ascoli AM, Goncalves SC, et al. Prevalence of resistant hypertension in non-elderly adults: prospective study in a clinical setting. Arq Bras Cardiol. 2012;99(1):630-5. 